OPEN ACCESS

Edited by:

Alexey Goltsov,

Abertay University, United Kingdom

Reviewed by:

Julian Borejdo,

Unversity of North Texas Health

Science Center, United States

Vladimir Danichev

Kurchatov Institute, Russia

${ }^{*}$ Correspondence:

Yuri Ivanov

yurii.ivanov@rambler.ru

lgor Goryanin

goryanin@gmail.com

Specialty section:

This article was submitted to

Vascular Physiology,

a section of the journal

Frontiers in Physiology

Received: 27 November 2017

Accepted: 29 June 2018

Published: 25 July 2018

Citation:

Ivanov $Y$, Kozlov AF, Galiullin RA, Tatur VY, Ziborov VS, Ivanova ND,

Pleshakova TO, Vesnin SG and

Goryanin I (2018) Use of Microwave

Radiometry to Monitor Thermal

Denaturation of Albumin.

Front. Physiol. 9:956.

doi: 10.3389/fphys.2018.00956

\title{
Use of Microwave Radiometry to Monitor Thermal Denaturation of Albumin
}

\begin{abstract}
Yuri Ivanov ${ }^{1 *}$, Andrey F. Kozlov ${ }^{1}$, Rafael A. Galiullin ${ }^{1}$, Vadim Y. Tatur ${ }^{2}$, Vadim S. Ziborov ${ }^{3}$, Nina D. Ivanova ${ }^{4}$, Tatyana O. Pleshakova ${ }^{1}$, Sergey G. Vesnin ${ }^{5,6}$ and Igor Goryanin ${ }^{7,8,9 *}$

${ }^{1}$ Institute of Biomedical Chemistry, Moscow, Russia, ${ }^{2}$ Foundation of Advanced Technologies and Innovations, Moscow, Russia, ${ }^{3}$ Joint Institute for High Temperatures of Russian Academy of Sciences (RAS), Moscow, Russia, ${ }^{4}$ Moscow State Academy of Veterinary Medicine and Biotechnology, Moscow, Russia, ${ }^{5}$ RES LTD, Moscow, Russia, ${ }^{6}$ Medical MicroWave Radiometry (MMWR) LTD, Edinburgh, United Kingdom, ${ }^{7}$ School of Informatics, University of Edinburgh, Edinburgh, United Kingdom, ${ }^{8}$ Biological Systems Unit, Okinawa Institute of Science and Technology, Okinawa, Japan, ${ }^{9}$ Tianjin Institute of Industrial Biotechnology, Chinese Academy of Sciences, Tianjin, China
\end{abstract}

This study monitored thermal denaturation of albumin using microwave radiometry. Brightness Temperature, derived from Microwave Emission (BTME) of an aqueous solution of bovine serum albumin $(0.1 \mathrm{mM})$ was monitored in the microwave frequency range $3.8-4.2 \mathrm{GHz}$ during denaturation of this protein at a temperature of $56^{\circ} \mathrm{C}$ in a conical polypropylene cuvette. This method does not require fluorescent or radioactive labels. A microwave emission change of $1.5-2^{\circ} \mathrm{C}$ in the BTME of aqueous albumin solution was found during its denaturation, without a corresponding change in the water temperature. Radio thermometry makes it possible to monitor protein denaturation kinetics, and the resulting rate constant for albumin denaturation was $0.2 \pm 0.1 \mathrm{~min}^{-1}$, which corresponds well to rate constants obtained by other methods.

Keywords: water clusters, protein denaturation, rate constant, microwave emission, temperature

\section{INTRODUCTION}

In medical studies, microwave radiometry (MWR) is based on the intensity of intrinsic electromagnetic radiation of the patient's tissues in the microwave range (Barrett and Myers, 1975; Carr, 1989; Leroy et al., 1998). MWR has found wide application in medical diagnostics (Carr, 1989; Leroy et al., 1998; Han et al., 2001; Stauffer et al., 2013, 2014; Livanos et al., 2018). To date, commercially available equipment has been developed to allow early diagnosis of cancers and other diseases (Vesnin, 2010) ${ }^{1}$. In the field of biochemical research, MWR is just starting to evolve (Ivanov et al., 2016a,b).

In this paper, the possibility of using MWR to study kinetics of protein denaturation is demonstrated. The study of thermal denaturation of proteins is important for understanding protein stability and for modeling their physicochemical properties. We used MWR to monitor the denaturation of albumin, the best characterized protein. Human serum albumin (HSA) is the most abundant protein in human blood plasma. Genes encoding HSA reside on chromosome 4 (Nishio and Dugaiczyk, 1996). Measurements of HSA are very important for diagnosis and treatment of many diseases (Anderson, 2000; Green et al., 2012). Since this protein is highly homologous to Bovine Serum Albumin (BSA) (Both are stabilized with 17 disulfide bonds and have the same

${ }^{1}$ Localized Cancer Tumor Detection Using Microwaves and Nanoparticles. Patent US15617440 registered (2017)-06-08, Priority date 2016-03-15. 
isoelectric point.), the latter is used in modeling the properties of HSA (Gelamo et al., 2002; Vetri et al., 2007). BSA contains 583 amino acids (Steinhardt et al., 1971; Hirayama et al., 1990; Gelamo et al., 2002; Moriyama et al., 2008; Ahmad et al., 2011) and has a molecular weight of $66.4 \mathrm{kDa}$. Its secondary structure consists mainly of alpha-helices. Denaturation and protein aggregation are generally investigated using scanning calorimetry and optical methods (Vetri et al., 2007; Borzova et al., 2016). The BSA denaturation rate constant at a temperature of $60^{\circ} \mathrm{C}$ is $0.5 \mathrm{~min}^{-1}$ (Borzova et al., 2016). Thus, using BSA denaturation as an example, this paper demonstrates the use of MWR in biochemical studies. Existing biochemical methods, including those used to study albumins (Steinhardt et al., 1971) typically have a number of disadvantages. Optical methods, such as circular dichroism methods require use of optical spectral instrumentation, which is quite expensive and may be difficult to operate. The drawbacks of calorimetry are the complexity and duration of the analysis. It should be noted, the advantages of using new methods in addition to known methods are that they provide more information about the denaturation processes under investigation.

In this work, new applications of this technique for measuring kinetics of albumin denaturation are demonstrated by monitoring the change in the brightness temperature in the microwave range. In the long term, development of MWR and its adaptation for studying other biochemical processes, could potentially result in a new analytical platform in biomedical research. MWR is easy to operate, does not require labels, and as noted earlier, can be used to study radiative properties of biological systems.

\section{MATERIALS AND METHODS}

De-ionized, ultrapure water (Milli-Q System, Millipore, USA) was used for all solutions. Lyophilized bovine serum albumin BSA [Sigma] was dissolved in deionized water at a concentration of $0.1 \mathrm{mM}$, close to the concentration of albumin in vertebrate blood (Fasano et al., 2005). pH of BSA solution was 7.00 \pm 0.05 .

\section{MEASUREMENT OF RADIOMETRIC BRIGHTNESS IN THE MICROWAVE RANGE}

We used a microwave radiometer RTM-01 RES (www.mmwr. co.uk) to measure electromagnetic radiation in the microwave range. The power of electromagnetic radiation in the frequency range $\Delta f$ of the medium is proportional to the radiometric (brightness) temperature of the medium $T_{\text {rad }}$ (Weisblat, 2003). For the microwave range, the power of the microwave signal at the antenna output can be represented as:

$$
P=k T_{\text {rad }} \Delta f(1-R),
$$

where $\Delta f$ is the frequency band of the microwave radiometer, in $\mathrm{GHz}$, and $k$ is Boltzmann's constant, $\mathrm{R}$ is the reflection coefficient of antenna, P- is the microwave radiation power of the heated aqueous medium of the protein received by the antenna.
The antenna is designed in such a way as to minimize the reflection coefficient $\mathrm{R}$. In addition, in the zero-balance radiometer used in the present studies, the measurement results are weakly dependent on the change in the reflection coefficient. Therefore, for balanced zero radiometers, $R=0$ is usually assumed. In accordance with eq. (1), by measuring the power of the radiation of the medium in the microwave range, it is possible to obtain information on the brightness $T_{\text {rad }}$ (Brightness Temperature derived from Microwave Emission, BTME), which characterizes the emissivity of the water-protein medium. The measurement range of $3.4-4.2 \mathrm{GHz}$ is selected based on the results of our early experiments (Ivanov et al., $2016 a, b)$. So, in this range we observed the radiation of a solution of enzyme biomolecules in the course of their functioning. The functioning is accompanied by the restructuring of the hydrate shells of bio-molecules, so we assumed that the melting processes of the protein can also lead to a rearrangement of its hydration envelope, and, consequently, to changes in the spectral characteristics of the water-protein medium in this frequency range. In addition, the convenience of using this range is determined by the fact that it operates commercial radiometers. We measured the BTME of water and the BTME of an aqueous solution of BSA in the microwave range 3.4-4.2 GHz. The error in measuring the BTME was $\pm 0.1^{\circ} \mathrm{C}$. To record radiation in the microwave range, a whip antenna connected to the microwave radiometer was used.

\section{PROCEDURE TO PREPARE SOLUTIONS FOR MEASUREMENT}

Water and $0.1 \mathrm{mM}$ aqueous protein solutions were heated using a thermostat (T-24, BIS, Russia) to a temperature of $56^{\circ} \mathrm{C}$, after which the sample was taken by pipette with a volume of $1 \mathrm{~mL}$. Measurements of BTME were carried out after the solution was injected into a conical polypropylene measuring cuvette with a conical base diameter of $25 \mathrm{~mm}$ and a height of $17 \mathrm{~mm}$. The cuvette was inserted into a thermostat Thermomixer Comfort (Eppendorf, Germany). Measurements were carried out for 25$60 \mathrm{~min}$. All measurements were repeated twice.

\section{RESULTS}

The control series of the experiments included measurements of BTME ( $\mathrm{t}$ ) of pure water and BSA solution at a temperature of $23^{\circ} \mathrm{C}$, when BSA denaturation is not observed. In either case, there was no change in BTME $(\mathrm{t})$ during the observation time of $22 \mathrm{~min}$.

Radiothermometry was used to monitor kinetics of thermal denaturation of BSA in water at a temperature of $\mathrm{T}=56^{\circ} \mathrm{C}$. We analyzed the BTME of an albumin solution in water, we have used the BTME of water as a control to exclude its possible effect on the results. During the observation time of $22 \mathrm{~min}$, changes in the BTME albumin solution were observed (see Figure 1), while from 25 to $60 \mathrm{~min}$ of observation, water and the BSA solution were practically unchanged (therefore no data in this time range are presented). The BTME of water did not change 


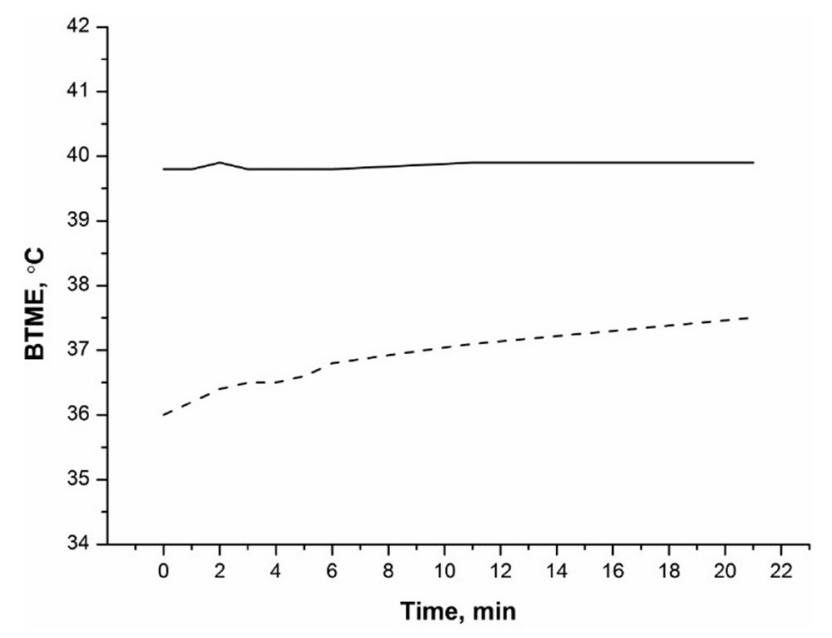

FIGURE 1 | Kinetics of thermal denaturation of $0.1 \mathrm{mM}$ BSA. BTME (BSA) (- - -), BTME (water) ( $\_$). The temperature of the solution was $56^{\circ} \mathrm{C}$. Measurements of microwave radiation were performed using an MWR-01 RES radiothermometer.

significantly with time (Figure 1). At the same time, the BTME of BSA changed significantly. During the initial period, the BTME of BSA was less than the BTME of water at $\sim 4^{\circ} \mathrm{C}$. During an observation time of about $25 \mathrm{~min}$, BTME of BSA increased on the order of $1.5-2^{\circ} \mathrm{C}$, (Figure 1). Error of experiment was of the order of $0.2^{\circ} \mathrm{C}$. The thermodynamic temperature of water and the albumin solution did not change during the experiment.

For better explanation of the experimental data, the effect of water was excluded, and a difference curve between the BTME of the protein solution and BTME of the water (control) was calculated. The difference between the BTME of BSA and that of water, $\triangle \mathrm{BTME}(\mathrm{t})=\mathrm{BTME}$ (BSA)-BTME (water), is shown in Figure 2 .

The $\triangle \mathrm{BTME}(\mathrm{t})$ of BSA decayed monotonically (Figure 2). This dependence was approximated by an empirical equation:

$$
\triangle B T M E(t)=A e^{-k_{d e n} t}+B
$$

where $A$ is the pre-exponential factor, $k_{d e n}$ is the denaturation rate constant, and $t$ is the time of measurement.

The thermal denaturation curve of albumin (Figure 2) is well described by the exponential curve (2) with $k_{d e n}=0.10 \mathrm{~min}^{-1}$, where $A=1.49, B=-3.77$. Approximation error BTME ( $\mathrm{t}$ ) does not exceed $0.2^{\circ} \mathrm{C}$. Average value of $k_{d e n}=(0.2 \pm 0.1) \mathrm{min}^{-1}$. Note that our data showing significant changes in BTME of BSA at $56^{\circ} \mathrm{C}$ is in agreement with experimental data derived from scanning calorimetry (Borzova et al., 2016), indicating that the BSA denaturation process should be observed in this temperature range. The denaturation rate constant at $60^{\circ} \mathrm{C}$, determined using scanning calorimetry, was $k_{d e n} \cong 0.5 \mathrm{~min}^{-1}$ (Borzova et al., 2016). Thus, the BTME (t) of BSA solution determined using MWR is close to that value. The reason for the BTME change in albumin solution during its thermal denaturation is as follows. First, it is known that while BSA denatures, the ratios

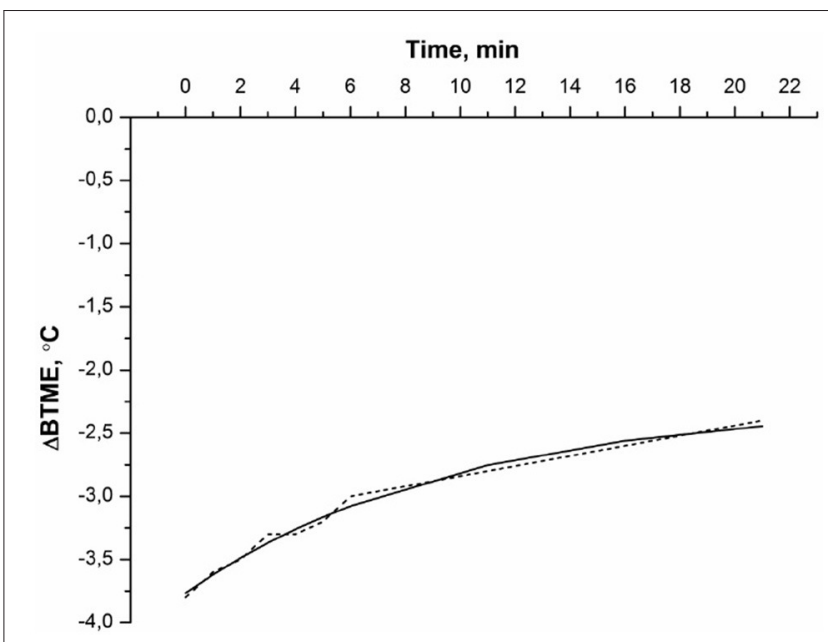

FIGURE 2 | The difference between the BTME of BSA and that of water: $\triangle \mathrm{BTME}(\mathrm{t})=\mathrm{BTME}(\mathrm{BSA})-\mathrm{BTME}$ (water). Experimental conditions were the same as in Figure 1. The experimental data (...), the approximation curve (_) according to eq. (2).

of ortho/para isomers of water change at the same time, as noted for chymotrypsin solution (Bunkin and Pershin, 2013). Second, as albumin denatures, it aggregates (Borzova et al., 2016), leading to a change in the ratio of ortho/para isomers of water (Pershin, 2013). The rotation spectrum of water isomers is in the $\mathrm{GHz}$ range (Bunkin and Pershin, 2013). These measurements are also made with a radiothermometer in the $\mathrm{GHz}$ band, so the denaturation of the protein leads to a change in the spectral properties of the solution within the sensitivity range of the instrument. Thus, MWR is well suited to monitoring protein denaturation.

MWR monitors the process of denaturation as a set of several processes described above, which allows refinement of models of protein denaturation. This method does not require any isotopes or fluorescent labels. It is simple and inexpensive compared with calorimetry and optical spectrometry and it allows quantum effects associated with the ratio of ortho/para isomers of water to be evaluated.

\section{DISCUSSION}

The work demonstrates that microwave radiometry allows direct monitoring of thermal denaturation of proteins, without the use of labels. This distinguishes it from complex methods using fluorescent labels or isotope tags. This method is much cheaper than circular dichroism or microcalorimetric methods. Within the microwave range, microwave radiometry makes it possible to monitor kinetics of protein denaturation associated with changes in these spectral properties of a medium containing a protein. These spectral properties are determined by the quantum-mechanical characteristics of this medium and provide information on the nature of the intermolecular interaction. Such characteristics include description the rotational transitions of water molecules to ortho- and para-states, the degree of 
disequilibrium of the aqueous medium in terms of its spin temperature, reflecting the complex heterostructure of water (Bunkin and Pershin, 2013). Moreover, some of the para-H2O molecules form hydrogen-bound complexes, for example, the structures of the hydrate shells of proteins (Pershin, 2013). The ratio of ortho/para isomers of pure water at constant temperature, as seen in Figure 1, does not change. However, in the presence of protein, the possible conversion of ortho/para isomers of water can be stimulated due to the change in the hydrate coat of the protein during its melting. The rotational transitions of hydroxy groups are in the $\mathrm{GHz}$ range, and the values of the detuning of the ortho/para states of the water molecules are also in this range (Pershin, 2013). In the same range, the spectral properties of the water-protein medium during the melting of the protein were measured. This allows us to suggest that changes in the brightness temperature of the medium measured in the range $3.4-4.2 \mathrm{GHz}$ during the melting of the protein are associated with a change in the ratio ortho/para isomers an aqueous medium. Therefore, using this method, it is possible to observe quantum mechanical transitions of ortho/para isomers an aqueous medium in a protein solution during denaturation process. Accordingly, it is possible to obtain new information for the theoretical modeling of protein denaturation when the protein interacts with an aqueous microenvironment.

Microwave radiometry has a high potential to become a standard method for studying physico-chemical properties of protein media. This is because in addition to characterizing the absorbing properties of aqueous protein solutions, microwave radiometry makes it possible to determine the radiative properties of enzyme solutions (Ivanov et al., 2016a,b) and to

\section{REFERENCES}

Ahmad, E., Sen, P., and Khan, R. H. (2011). Structural stability as a probe for molecular evolution of homologous albumins studied by spectroscopy and bioinformatics. Cell Biochem. Biophys. 61, 313-325. doi: 10.1007/s12013-011-9214-4

Anderson, D. M. (2000). “Dorland's illustrated medical dictionary," Philadelphia [u.a.], $29 E d n$, Saunders. 860.

Barrett, A. H., and Myers, P. C. (1975). Subcutaneous temperature: a method of noninvasive sensing. Science 190, 669-671.

Borzova, V., Markossian, K., Chebotareva, N., Kleymenov, S., Poliansky, N.,Muranov, K., et al. (2016). Kinetics of thermal denaturation and aggregation of bovine serum albumin. PLOS ONE 11:e0153495. doi: 10.1371/journal.pone.0153495

Bunkin, A. F., and Pershin, S. M. (2013). Coherent laser spectroscopy of processes of hydration of biomolecules and nanoparticles. Proc. Instit. Gen. Phys. A 69, $58-69$.

Butrov, A. V., Shevelev, O. A., Cheboksarov, D. V., and Khodorovich, N. A. (2012). Non-invasive daily thermocartication of the brain in the dynamics of ischemic stroke with craniocerebral hypothermia. Bull. Pfur Ser. Med. 7, 62-64. doi: 10.3389/fneur.2011.00080

Carr, K. L. (1989). Microwave radiometry: its importance to the detection of cancer. IEEE MTT 37, 1862-1869. doi: 10.1109/22.44095

Fasano, M., Curry, S., and Terreno, E. (2005). IUBMB. Life 57, 787-796.

Gelamo, E. L., Silva, C. H. T. P., Imasato, H., and Tabak, M. (2002). Interaction of bovine (BSA) and human (HSA) serum albumins with ionic surfactants: spectroscopy and modelling. Biochim. Biophys. Acta 1594, 84-99. doi: 10.1016/S0167-4838(01)00287-4 monitor cellular functions in the microwave range (Zynov'ev and Vesnin, 2009; Ivanov et al., 2016c).

\section{FUTURE APPLICATIONS IN BRAIN STROKE AND TRAUMA}

The brightness temperature of water and protein solutions at physiological temperatures (Zynov'ev and Vesnin, 2009; Ivanov et al., 2016d, 2017; Vesnin et al., 2017), should permit applications this method in diagnostics of human and animal hemodynamics and for describing processes of water balance in living systems. In clinics, MWR has been successfully used for breast cancer (Vesnin et al., 2017), Among other clinical applications, MWR has long been used to monitor brain damage (Butrov et al., 2012) after stroke and other brain injuries. In the future, microwave radiometry could have clinical applications in stroke and trauma.

\section{AUTHOR CONTRIBUTIONS}

YI supervised the project. AK, RG, VT, VZ, and NI carried out the experiments. TP carried out the experiments and wrote the paper. SV provided equipment and consultancy. IG wrote the paper and provided consultancy.

\section{ACKNOWLEDGMENTS}

This work was supported by the Program for Basic Research of State Academies of Sciences for 2013-2020.

Green, P., Woglom, A. E., Genereux, P., Daneault, B., Paradis, J. M., Schnell, S., et al. (2012). The impact of frailty status on survival after transcatheter aortic valve replacement in older adults with severe aortic stenosis: a singlecenter experience. JACC Cardiovasc. Interv. 5:974-981. doi: 10.1016/j.jcin.2012. 06.011

Han, J. W., Van Leeuwen, G. M., Mizushina, S., Van de Kamer, J. B., Maruyama, K., Sugiura, T., et al. (2001). Monitoring of deep brain temperature in infants using multi-frequency microwave radiometry and thermal modelling, Phys. Med. Biol. 46, 1885-1903.

Hirayama, K., Akashi, S., Furuya, M., and Fukuhara, K. (1990). Rapid confirmation and revision of the primary structure of bovine serum albumin by ESIMS and Frit-FAB LC / MS. Biochem. Biophys. Res. Commun. 173, 639-646. doi: 10.1016/S0006-291X(05)80083-X

Ivanov, Y. D., Kozlov, A. F., Malgagova, K. A., Pleshakova, T. O., Vesnin, S. G., Tatur, V., et al. (2016a). Monitoring of microwave emission of HRP system during the enzyme functioning. Biochem. Biophys. Rep. 7, 20-25. doi: 10.1016/j.bbrep.2016.05.003

Ivanov, Y. D., Malgagova, K. A., Izotov, A. A., Pleshakova, T. O., Tatur, V. Y., Vesnin, S. G., et al. (2016b). Detection of microwave radiation of cytochrome CYP102 A1 solution during the enzyme reaction. Biochem. Biophys. Rep. 5, 285-289 doi: 10.1016/j.bbrep.2015.12.013

Ivanov, Y. D., Malsagova, K. A., Pleshakova, T. O., Vesnin, S. G., Tatur, V. Y., and Yarygin, K. N. (2016c). Monitoring of brightness temperature of suspension of follicular thyroid carcinoma cells in SHF range by radiothermometry [in Russ]. Patol. Fiziol. Eksp. Ter. 60, 174-177.

Ivanov, Y. D., Malsagova, K. A., Tatur, V. Y., Vesnin, S. G., Ivanova, N. D., and Ziborov, V. S. (2016d). SHF radiation from albumin solution upon external excitation [in Russ]. Patol. Fiziol. Eksp. Ter. 60, 101-104. 
Ivanov, Y. D., Kozlov, A. F., Galiullin, R. A., Tatur, V. Y., Vesnin, S. G., Ziborov, V. S., et al. (2017). Monitoring of brightness temperature fluctuation of water in SHF range [in Russ]. Patol. Fiziol. Eksp. Ter. 61, 101-107.

Leroy, Y., Bocquet, B., and Mammouni, A. (1998). Non-invasive microwave radiometry thermometry Physiol. Meas. 19, 127-148. doi: 10.1088/0967-3334/19/2/001

Livanos, N. A., Hammal, S., and Nikolopoulos, C. D. (2018). Design and interdisciplinary simulations of a hand-held device for internal-body temperature sensing using microwave radiometry IEEE Sens. J. 18, 2421-2433. doi: 10.1109/JSEN.2018.2791443

Moriyama, Y., Watanabe, E., Kobayashi, K., Harano, H., Inui, E., and Takeda, K. (2008). Secondary structural change of bovine serum albumin in thermal denaturation up to 130 degrees $\mathrm{C}$ and protective effect of sodium dodecyl sulfate on the change. J. Phys. Chem. 112, 16585-16589. doi: 10.1021/jp8067624

Nishio, H., and Dugaiczyk, A. (1996). Complete structure of the human alpha-albumin gene, a new member of the serum albumin multigene family. Proc. Nat. Acad. Sci. U.S.A. 93, 7557-7561. doi: 10.1073/pnas.93.1 5.7557

Pershin, S. M. (2013). "New conception of influence of EMF to water/solution taking into account of quantum ortho/para distinguish of spin $\mathrm{H} 2 \mathrm{O}-$ isomers, IV International conference,"in Human and Electromagnetic Fields (Sarov).

Stauffer, P. R., Rodriques, D. B., and Salahi, S. (2013). "Stable microwave radiometry system for long term monitoring of deep tissue temperature," in Proceedings of the SPIE (San Francisco, CA) 0R1-11.

Stauffer, P. R., Snow, B. W., and Rodrigues, D. B. (2014). Non- invasive measurement of brain temperature with microwave radiometry: demonstration in a head phantom and clinical case. Neuroradiol. J. 27, 3-12. doi: 10.15274/NRJ-2014-10001
Steinhardt, J., Krijn, J., and Leidy, J. G. (1971). Differences between bovine and human serum albumins: binding isotherms, optical rotatory dispersion, viscosity, hydrogen ion titration, and fluorescence effects. Biochemistry 10, 4005-4015. doi: 10.1021/bi00798a001

Vesnin, S. G., Turnbull, A. K., Dixon, M., and Goryanin, I. (2017). Modern microwave thermometry for breast cancer. J. Mol. Imag. Dynamic. 7:136. doi: 10.1109/ICIIBMS.2017.8279720

Vesnin, S. G. (2010). The Antenna Applicator and a Device for Determining the Temperature Changes and Detection of Cancer. Patent 2008151958/14, RF; (in Russian).

Vetri, V., Librizzi, F., Leone, M., and Militello, V. (2007). Thermal aggregation of bovine serum albumin at different $\mathrm{pH}$ : comparison with human serum albumin. Eur Biophys. 36, 717-725. doi: 10.1007/s00249-007-0196-5

Weisblat, A. V. (2003). Radiothermography as a Method of Diagnosis in Medicine$M$; NTSZD RAMS.-67s.

Zynov'ev, S. V., and Vesnin, S. G. (2009). Functional microwave radiometry of malignant tumours: experimental study medical physics. 4, 51-58. (In Russ).

Conflict of Interest Statement: The authors declare that the research was conducted in the absence of any commercial or financial relationships that could be construed as a potential conflict of interest.

Copyright (ङ 2018 Ivanov, Kozlov, Galiullin, Tatur, Ziborov, Ivanova, Pleshakova, Vesnin and Goryanin. This is an open-access article distributed under the terms of the Creative Commons Attribution License (CC BY). The use, distribution or reproduction in other forums is permitted, provided the original author(s) and the copyright owner(s) are credited and that the original publication in this journal is cited, in accordance with accepted academic practice. No use, distribution or reproduction is permitted which does not comply with these terms. 